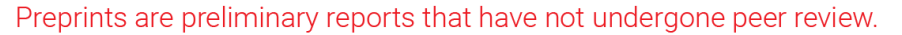 They should not be considered conclusive, used to inform clinical practice, or referenced by the media as validated information. \\ Evaluation of Bolt and Guide Rail Considering Surface Roughness and Bionics in Reciprocating Motion
}

Jian Xu ( $\nabla$ zdp12_0@126.com )

North University of China https://orcid.org/0000-0002-3055-3736

Zhen Yang

North University of China

Qiang Li

North University of China

Zhongming Li

PERA of China

Original Article

Keywords: Coupling thermal-structural analysis, Surface roughness, Bionics, Reciprocating motion, Sliding Friction Pairs

Posted Date: July 8th, 2021

DOI: https://doi.org/10.21203/rs.3.rs-681951/v1

License: (9) This work is licensed under a Creative Commons Attribution 4.0 International License. Read Full License 


\section{Title page}

\section{Evaluation of Bolt and Guide Rail considering Surface Roughness and Bionics in Reciprocating Motion}

Jian Xu, born in 1979, is currently a Ph.D. lecture, North University of China. He received his PH.D. degree from North University of China, China, in 2010. His research interests include friction and motion, and weapon movement..

Tel: +86-15803431078; E-mail:zdp12_0@126.com

Zhen Yang, born in 1965, is currently a Professor , PH.D, North University of China. He received his PH.D. degree from Xi'an Jiaotong University, China, in 2002.

Qiang Li, born in 1971.is currently a Professor, PH.D., North University of China. He received his PH.D degree from North University of China, China, in 2005.

Zhong-ming Li, born in 1980, is currently an engineer in PERA of China, China.

Corresponding author: Jian Xu E-mail: zdp12_0@126.com 


\title{
Evaluation of Bolt and Guide Rail considering Surface Roughness and Bionics in Reciprocating Motion
}

\author{
Jian $\mathrm{Xu}^{1^{*}} \cdot$ Zhen Yang${ }^{1} \cdot$ Qiang $^{\mathrm{Li}^{1}} \cdot$ Zhong-ming $\mathrm{Li}^{1,2}$
}

Received June xx, 201x; revised February xx, 201x; accepted March xx, 201x

(C) Chinese Mechanical Engineering Society and Springer-Verlag Berlin Heidelberg 2017

\begin{abstract}
*Abstract: The temperature rise in the contact area of the sliding friction pair is an important factor that causes the sliding friction pairs to adhere and affect the movement, and the temperature of the sliding friction pair is affected by many factors. The influential trend of these factors on the temperature is analyzed by using the finite element software, the bolt and guide rail of a Gatling weapon is simulated under the condition of considering the surface roughness and bionics.

The results demonstrate that the stress of the result decreases a lot when the bolt is bionic, which is $41.1 \%$ lower than the normal condition. However, the displacement increases slightly, only $0.0016 \mathrm{~mm}$. Bionics has more benefits than roughness in reducing stress.

In the thermal situation analysis of the 10000 firing rate, the combination which comes from the general guide rail and the bionics bolt is $168.13^{\circ}$, but the combination which comes from the general guide rail and general bolt is $86.258^{\circ}$. This also explains why modern Gatling weapons do not use the bionics structure, because, with the friction, its temperature is high. For continuous firing weapons, too high a temperature is a problem. If the firing rate is lower, a bionics structure can be used.
\end{abstract}

\section{Keywords:}

Coupling thermal-structural analysis; Surface roughness; Bionics; Reciprocating motion; Sliding Friction Pairs

\footnotetext{
$\bowtie$ Jian Xu

Zdp12_0@126.com

1 College of Mechatronics Engineering, North University of China, Taiyuan 030051, PR China 310027, China

2 PERA of China, Beijing 100089, PR China
}

\section{Introduction}

The friction between the bolt body and the guide rail of the Gatling weapon has not been seen in the literature, so this paper introduces the roughness and bionics point of view when studying the friction between the bolt body and the guide rail, hoping to attract everyone's attention.

The contact interface property is so crucial that it will affect macro-mechanical performance, such as friction, wear, assembly relation, tightness, fatigue strength, etc. To obtain the contact behaviors of bolt/guide rail accurately.

Tribology is the study of friction, lubrication, and wears on the surface of relative motion, and the marginal subject of the theory and application of interrelationships. For different conditions (such as materials, loading, speeding, etc.), the contact conditions, such as temperature field, stress distribution, contact deformation, and wear tendency of the friction pair, are analyzed. Han[1] explained this application range of static friction coefficient, Wang[2] explained the dynamic friction coefficient of metal materials, and Wang[3] explained the sliding friction and its physical explanation. Gong[4] explained the calculation method of the sliding friction coefficient. Liu[5] explained the measurement of cylinder rolling friction. Guo[6] explained that the rolling friction coefficient comes from the measurement.

Friction and wear[7-9] not only consume energy and materials, but also reduce the labor and material resources required for the replacement of parts, repairs, and stoppages due to friction and wear, as well as the reduction in production labor rate.

Real engineering surfaces are not completely smooth. When two objects are in contact with each other, the real surface is the contact between the micro-convex bodies. 
Analyzing contact between real rough surfaces plays a key role in studying friction, wear and lubrication.

The generation of frictional heat is mainly related to the sliding friction coefficient, contact load, and sliding speed between the contact interfaces[10-12].

In engineering practice, the generation of frictional heat will cause serious damage to important engineering surfaces. The frictional sliding surfaces that are in contact with each other are rough, so it has important theoretical significance for the flash temperature and thermal-mechanical stress analysis of rough surfaces in micro-interval engineering.

The surface damage behavior of friction pair refers to the development process of damage mode and depth of damage layer of friction pair material under specific working conditions and environmental conditions. It is the result of multiple factors such as environmental working conditions and lubrication of friction pair material[13-14].

For a long period, the high-speed and high-speed motion of contacting friction pairs[15], due to the heat generated by friction, the temperature rise in the contact area, it will cause the adhesion and wear phenomenon, which seriously affects the normal work of the friction pair[16].

With the development of the economy, green manufacturing has become an important means to address resource shortages and environmental degradation. Research on the wear of bolt/rail mechanisms is also one of the specific issues facing green manufacturing.

\section{Gatling Principle and Bolt/Guide Rail mechanism}

\subsection{Process interpretation}

Gatling weapon[15] system loading system has always been very important. The bullets are pushed and the Gatling weapon maintains forward and backward motion. The simplified transmission diagram is shown in Figure. 3

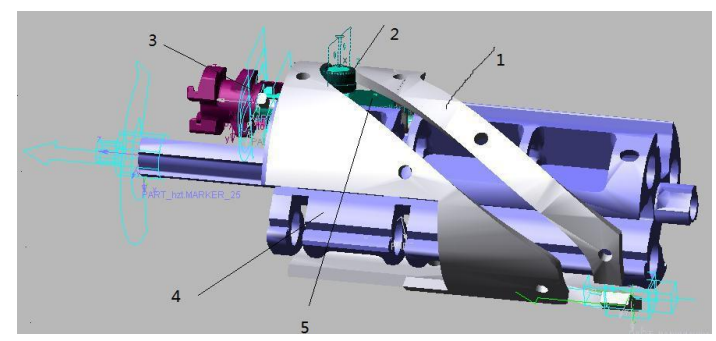

1-the outer cam 2-the main roller axis 3-the bolt head 4-the revolving body 5-bolt assembly

Figure 3 Gatling weapon
The bolt assembly has three components, including the main roller axis, main roller, and bolt body, as Fig.4 shows. The force is like Fig.5, the outer cam gives the main roller $F_{N}$, the outer cam gives the main roller friction force $\mathrm{F}$.

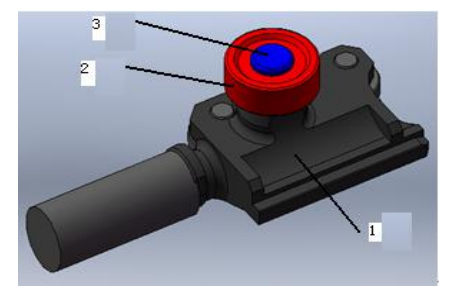

1-bolt body 2-main roller 3-main roller axis

Figure 4 Bolt assembly

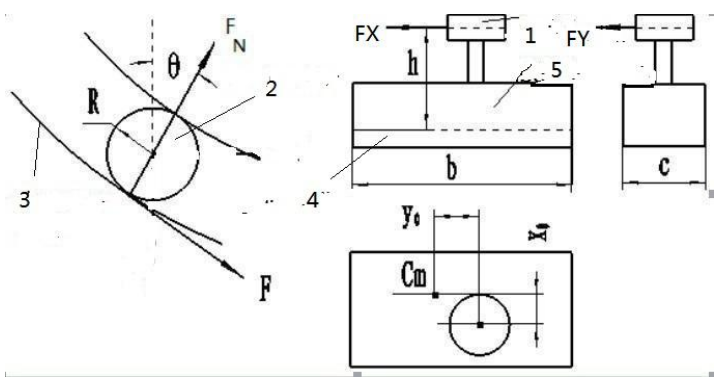

1,2-main roller 3-the outer cam 4-guide rail 5-bolt

Figure 5 Bolt assembly

This is the kinematic equation, each item can be seen in the paper[15,16]:

$$
\begin{aligned}
& m a=F X-2 f \frac{F X h}{b}-2 f \frac{F Y h}{c}-2 f \frac{F X x_{0}}{b} \\
& -2 f \frac{F Y y_{0}}{b}-f m r_{1} \omega_{1}^{2}-f m r_{l}^{2} \varepsilon_{1}-f F Y
\end{aligned}
$$

\subsection{Bolt/Guide Rail Mechanism}

\subsubsection{Surface Roughness modeling}

The wear surface morphology can be reflected by two-dimensional and three-dimensional surface profiles. The three-dimensional surface morphology focuses on the study of the changes in the overall structure of the work surface, which can reflect the changes of the worn surface in different regions. The collection method and calculation formula are relatively complex.

There are two methods to model rough surfaces. One is the Green-Williamson model based on Gaussian distribution[18]. This model assumes that the contact part consists of a plane with infinite stiffness and a surface composed of many hemispheres with the same radius. The other method is the fractal geometry method to model and analyzes rough surfaces[19].

In engineering, almost all machined surfaces have some sort of texture features. As a spatial feature, texture can hardly be described by a single parameter of surface 
topography. So the steps to generate a rough surface with a specified autocorrelation function are as follows[20-21]:

A 3D fractal surface topography can be generated using a modified(truncated) two-variable Weierstrass-Mandelbrot fractal function that can be written as[19]

$$
\begin{aligned}
& Z(x, y)=L\left(\frac{G}{L}\right)^{(D-2)}\left(\frac{\ln \gamma}{M}\right)^{1 / 2} \stackrel{M}{M_{m=1}^{n_{m a x}}} \gamma^{(D-3) n} \times \\
& \left\{\cos \phi_{m, n}-\cos \left[\frac{2 \pi \gamma^{n}\left(x^{2}+y^{2}\right)^{1 / 2}}{L} \times \cos \left(\tan ^{-1}\left(\frac{y}{x}\right)\right.\right.\right. \\
& \left.\left.\left.-\frac{\pi m}{M}\right)+\phi_{m, n}\right]\right\}
\end{aligned}
$$

Where: $\mathrm{L}$ is the sample length, $\mathrm{G}$ is the fractal roughness, $\mathrm{D}$ is the fractal dimension $(2<\mathrm{D}<3), \gamma(\gamma>1)$ is a scaling parameter, $M$ is the number of superposed ridges used to construct the surfaces, $\mathrm{n}$ is a frequency index, with $\mathrm{n}_{\max }$ $=\operatorname{int}[\log (\mathrm{L} / \mathrm{Ls}) / \log \gamma]$ representing the upper limit of $n$, where Ls is the cut-off length and $\varphi_{\mathrm{m}, \mathrm{n}}$ is a random phase. The scaling parameter $\gamma$ controls the density of frequencies in the surface profile.

The fractal dimension $\mathrm{D}$ is larger, the surface morphology is smoother. $G$ is a frequency-independent height scaling parameter, which can be determined by experiments (the larger the value of $G$, the rougher the profile of surface topography). The fractal roughness $G$ is a height scaling parameter independent of frequency within the scale range where fractal power-law behavior is observable. Physically, higher $G$ values correspond to rougher(less dense) surface topographies[20].

According to $\mathrm{Xu}$ Zhiqian's papers[21], it is given the paper:

$$
D=1.7759 * R_{a}^{0.2147}
$$

Because the roughness $\mathrm{Ra}$ and the fractal roughness $\mathrm{G}$ satisfy the following relationship[22-23]:

$$
R_{a} \infty G^{D_{-}}
$$

Therefore, another parameter $\mathrm{G}$ is obtained.

The topography of the rough surface has a fractal feature. The fractal characteristics of the rough surface are independent of the scale and can provide all the roughness information of all scale ranges existing on the fractal.

As a typical tribological system, the guide rail pair maintains its accuracy by wear. Rough surface features and frictional contact models are the first problems to understand in terms of friction and wear.

The traditional measurement methods and evaluation methods can not describe the surface morphology at several $\mathrm{nm}$ scales[23]. Therefore, a new evaluation parameter must be used to describe the surface topography at $\mathrm{nm}$ scale. Fractal geometry is used to analyze, evaluate and model the surface morphology, which can provide the characteristics of surface morphology at all scales. And the Ansys unit changes with our requirements.

Using reverse engineering technology to reconstruct the surface roughness in SolidWorks. The ScanTo3D from Solidworks can quickly generate 3D models from scanned data or Xyz data.

Figure 6 is the most Ra $3.2 \mathrm{um}$ surface roughness of bolt and guide rail physical model, and Figure 7 shows the structure of the guide rail, and Figure 8 shows the guide rail with the elevation of 0 degrees and angle of view of 90 degrees.

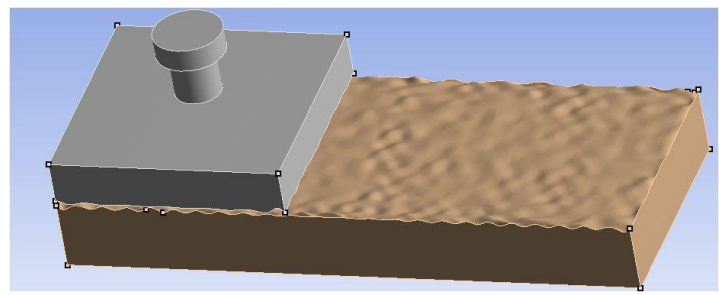

Figure 63.2 um physical model

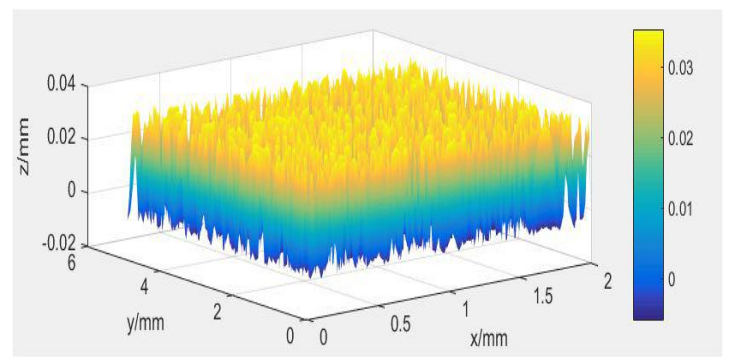

Figure 73.2 um the guide rail from the front

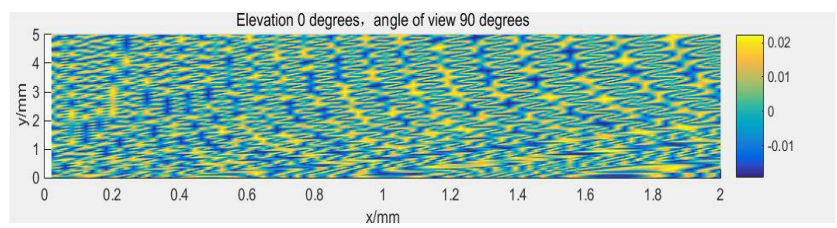

Figure 8 guide rail of elevation 0 degrees and angle of view 90 degrees

Thus the bolt and guide rail was enlarged by 1000 times. After the model is built, it is reduced by 0.001 , thus returning to the original model. In this case, the pressure and deformation can be calculated.

\subsubsection{Bionic and General Motion}

There are four parameters in the bolt cam part[23-25]: 1)interval length $\mathrm{x} 2$;2)interval width $\mathrm{x} 1$; 3)radius $\mathrm{R} ; 4$ ) angles $\theta$ are the most reliable in flatbed, as Figure 9 .

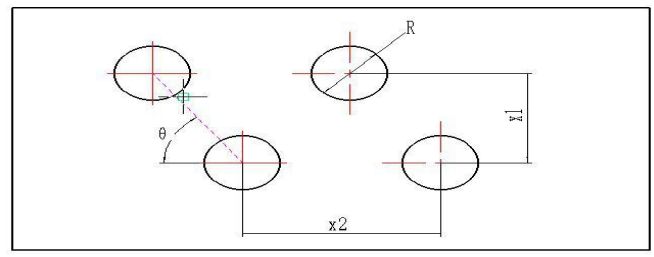


Figure 9 four parameters in bolt cam part

After studying the motion performance of high-speed sliding pair, we found that its friction and wear properties, friction between the two blocks of the same materials, and it is two kinds of friction between steel plates. There is some lubrication of the material like a lubricant that has its impact and wear. Then, the wear prediction model of the tribological system is put forward. It is expected that the number of columns, the size of the gap, and the size of the holes will be used. With Yang Z's[25] conclusion.

Discarded as useless with friction and wear of the contact surfaces, new ways are based on reconstructing surface morphology by laser texturing techniques. It used some round hole with a diameter of $150 \mathrm{um}$ and spacing of $600 \mathrm{um}$. Some typical organisms surfaces, for example, seashell 、 tooth and dung bettle[23-25], similar to industry rollers wear. The force which acts on the rails changes very quickly, and the force acts in the positive direction, while the contact surface of the bottom surface is stressed. At another time, the force acts in the opposite direction, and the force is applied by the top surface. which is as Figure. 10-11. To make a comparison, the comparison between ordinary rails (AK630, as Figure.11(b)) and bionic rails as Figure 11(a).

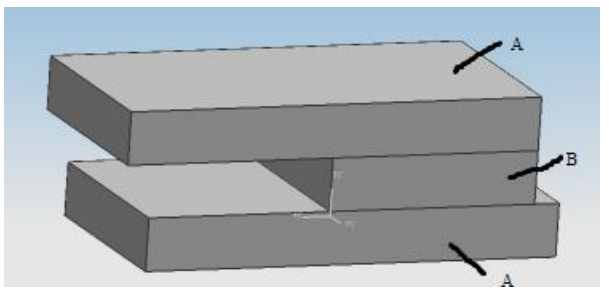

A-Upper-lower rails B-main roller guide

Figure 10 Bolt cam part with two guides

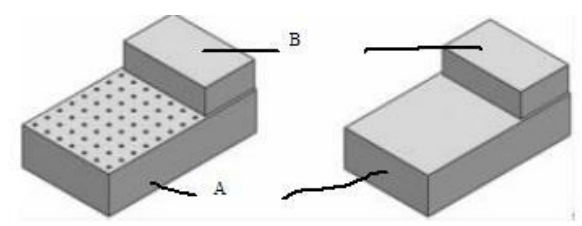

A-Upper-lower rails B- main roller guide

Figure 11 Bionic and General Motion

\subsubsection{Different firing rates to different heavy loads}

As Jian $\mathrm{Xu}[16]$ puts forward the relationship between the firing rates and the force of the main roller:

Table 1. Firing rate and Min or Max $F N$

\begin{tabular}{ccc}
\hline Fire ratio & Min & Max \\
& $F N(\mathrm{~N})$ & $F N(\mathrm{~N})$ \\
\hline 3300 & 913.7 & 1086.5 \\
\hline 6000 & 3654.9 & 4346.3 \\
\hline 10000 & 8223.5 & 9779.3 \\
\hline 12000 & 11193.1 & 13310.8 \\
\hline
\end{tabular}

$F X, F Y$ is related to $F N$ in this way:

$F X=F N \cos \theta$

$F Y=F N \sin \theta$

The FX, FY of 10000 fire ratio are shown in Figure 12:

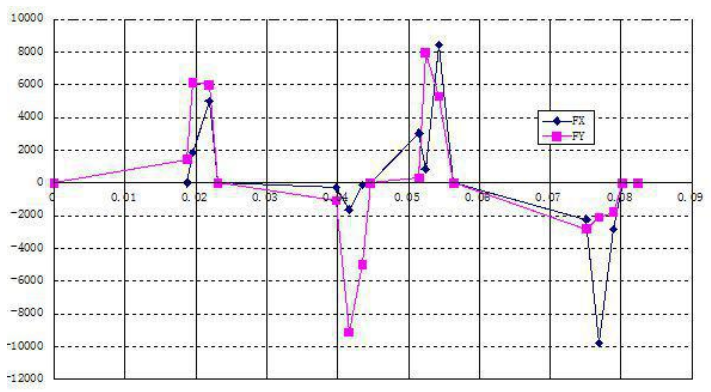

Figure 1210000 FR FN to its respective force FX, FY As Figure 12 shows the FX, FY direction, thus the maximum value $\mathrm{FX}$ is about $8200 \mathrm{~N}$ at time of $0.05 \sim 0.06$, the maximum value $\mathrm{FY}$ is about $8000 \mathrm{~N}$ at time of $0.05 \sim 0.06$.

\subsection{Sliding friction-thermal modeling}

This research on the heating analysis of the surface sliding friction process will be helpful to expose the mechanism of the surface damage. Thermal structural coupling analysis is used to calculate the stress, temperature distribution, and other of a system or component thermophysical parameters, such as heat gain or loss, thermal gradient, heat flux, etc. After the contact model is established, there are two main methods of analysis: analytical method and numerical method[26-27].

The contact surface of the guide rail pair is mechanically processed. It is a smooth surface in a macroscopic view, but when viewed under a microscope, it is covered with uneven peaks and valleys. When two rough surfaces are contacted by a load, the first contact is where the sum of the heights of the micro-convex bodies of the two surfaces is the highest. As the load increases, other new pairs of micro convex bodies will also come into contact. In this paper, finite element analysis (FEM) software was used to analyze and establish the contact prediction type, which made preliminary preparations for the friction and wear research of the guide rail pair. 
In engineering, for long-term high-speed and high-speed sliding friction pairs that are in contact with each other, the temperature increase in the contact area will cause the adhesion and wear phenomenon, which seriously affects the normal movement of the friction pair. Due to its high relative sliding speed and high temperature, the wear problem is very serious[27-29].

Friction and wear analysis involves large elastoplastic deformation, so the material must be defined as plastic strengthening law, according to the characteristics of friction and wear, it selects bilinear isotropic strengthening in ANSYS BISO (bilinear isotropic stress-harding option) option.

Total heat generated by friction[30]:

$$
Q=\frac{\mu F v}{J}
$$

Where: $\mu$ is the dynamic friction coefficient, $F$ is the pressure load applied on the sliding block; $v$ is the relative velocity of the slider; $J$ is the thermal work equivalent, and the value is $4.2 \mathrm{~J} / \mathrm{cal}$. The uint of $Q$ is $W / \mathrm{m}^{2}$

Due to constant wear and tear, huge heat is generated between the body and the guide rail, the sliding distance is $\mathrm{L}=1800 \mathrm{~mm}$ to simplify the calculation. The couple system analysis is these two systems: The influence of wear test parameters is investigated through finite element simulation model tests, to reveal the wear mechanism and law and provide a basis for the design of tribological systems and practical engineering applications.

The contact surface of the guide rail pair is mechanically processed. It is a smooth surface in a macroscopic view, but when viewed under a microscope, it is covered with uneven peaks and valleys. When two rough surfaces are contacted by a load, the first contact is at the position where the sum of the height of the micro-convex bodies of the two surfaces is the maximum. As the load increases, other new pairs of micro convex bodies will also come into contact. The temperature-dependent material parameters were as presented in table 3:

Table 3 Temperature-dependent material parameters

\begin{tabular}{lrlllllllc}
\hline $\mathrm{t}$ & & $\mathrm{E}$ & $\mu$ & $\sigma_{0}$ & $\lambda$ & \multicolumn{1}{c}{$C_{n}$} & $\alpha$ \\
\hline 2 & 0 & 210 & 0.286 & 600 & 52.34 & 43 & 4 & 11.52 \\
1 & 0 & 0 & 207 & 0.289 & 600 & 48.85 & 490.7 & 12.56 \\
2 & 0 & 0 & 202 & 0.300 & 600 & 44.19 & 527.2 & 13.47 \\
3 & 0 & 0 & 192 & 0.319 & 600 & 41.87 & 565.9 & 14.89 \\
\hline
\end{tabular}

Where: t-temperature $\left(^{\circ}\right)$;

E-Young's modulus(GPa); $\sigma_{0}$-Yield stress(MPa); $\lambda$ Thermal Conductivity(WK-1m-1); $\quad C_{p}$-Specific heat capacity $\left(\mathrm{Jg}^{-1} \mathrm{~K}^{-1}\right) ;{ }^{\alpha}$-Thermal expansion $\left(\times 10^{-6} \mathrm{~K}^{-1}\right)$
According to the theory of heat transfer, the heat conduction equation of isotropic material without an internal heat source is[17]:

$$
\frac{\partial^{2} T}{\partial x^{2}}+\frac{\partial^{2} T}{\partial y^{2}}+\frac{\partial^{2} T}{\partial z^{2}}=\frac{\rho C}{\lambda} \frac{\partial T}{\partial t}
$$

Where: $T$ is temperature, $K ; t$ is time, $s ; \rho$ is material density, $\mathrm{kg} / \mathrm{m}^{3} ; C$ is the material-specific heat capacity, $J \mathrm{~kg}^{-1} \mathrm{~K}^{-1}, \lambda$ is the thermal conductivity, WK-1m-1.

When initial time $\mathrm{t}=0$;

$$
T(x, y, z)=T_{0}
$$

On the interface involved in friction[31-33]:

$$
-\lambda \frac{\partial T}{\partial z}=-q+\alpha_{z}\left(T-T_{0}\right)+\varepsilon_{z} \sigma\left(T^{4}-T_{0}^{4}\right)
$$

On all heat exchange interfaces:

$$
-\lambda \frac{\partial T}{\partial n_{i}}=\alpha_{i}\left(T-T_{0}\right)+\varepsilon_{i} \sigma\left(T^{4}-T_{0}^{4}\right)
$$

In the Eq.(3)-Eq.(5), $T_{0}$ is the ambient temperature; $q$ is the heat flux absorbed, $W / m^{2} ; \alpha_{z}$ is the convective heat transfer coefficient of friction interface, $W /\left(m^{2} K\right)$, $n_{i}$ is the normal unit of each interface vector; $\sigma$ is Stephen-Boltzmann constant, $5.67032 * 10^{-8} \mathrm{~W} /\left(\mathrm{m}^{2} . \mathrm{K}^{4}\right)$ , $\alpha_{i}$ is the convective heat transfer at each interface thermal coefficient, $W /\left(m^{2} K\right) ; \varepsilon_{i}$ is the radiation heat transfer coefficient of each interface, $W /\left(m^{2} . K\right)$.

\section{Results and Discussions}

It is discussed in bionic motion associated with the general motion. the bolt and guide rail system is shown in Figure. 13 which is used in 10000 firing rate :

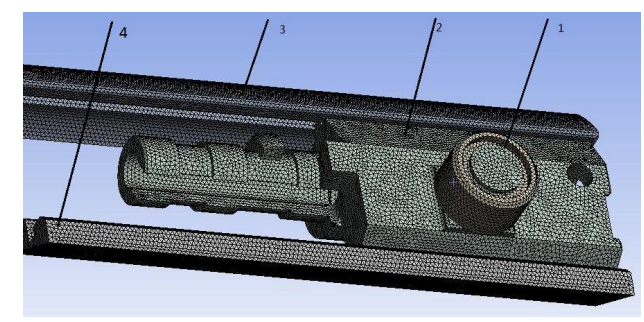

1-main roller 2- bolt 3-right rail 4-left rail

Figure 13 Bolt and guide rail system

There have four pairs, the general or bionics rail, and the general or bionics bolt. Thus the results are as follows.

\section{1 the bolt and guide rail stress}

\subsection{1 the general rail and the general bolt}

Used $F_{N}$ to the main roller as Figure 12, and used the standard earth gravity, the other rail is fixed. The general rail stress and displacement are analyzed as Figure.14-15: 


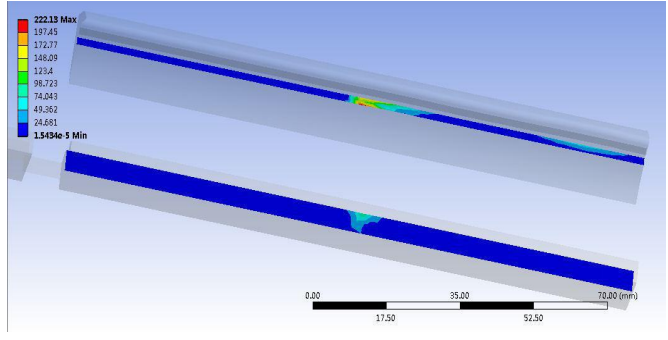

Figure 14 The general rail stress analysis

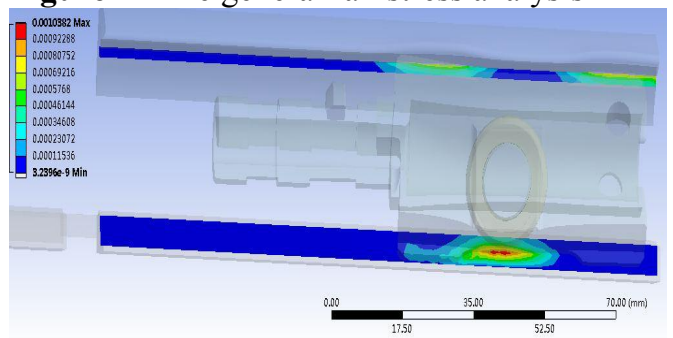

Figure 15 The general rail displacement analysis

\subsection{2 the bionics rail and the general bolt}

The bionics rail and the general bolt, the stress and displacement results are Figure 16-17 :

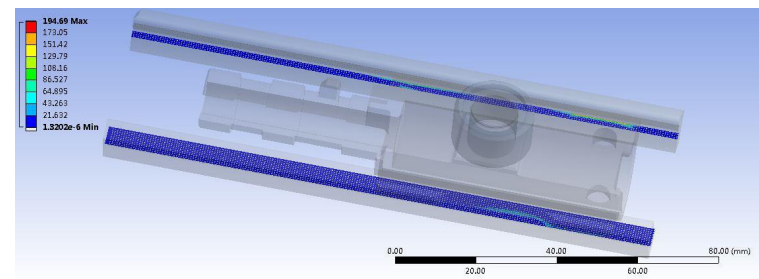

Figure 16 the bionic rail stress analysis

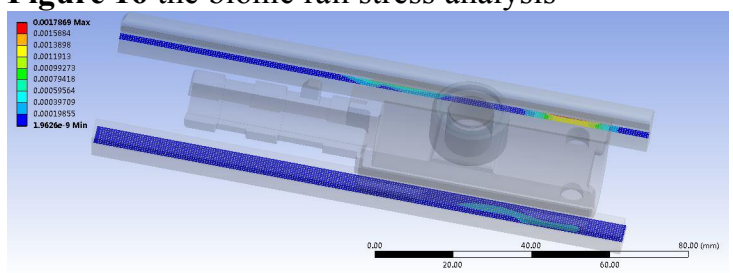

Figure 17 the bionic rail displacement analysis

\subsection{3 the general rail and the bionics bolt}

The general rail and the bionics bolt, the stress and displacement results are analyzed as Figure 18-19:

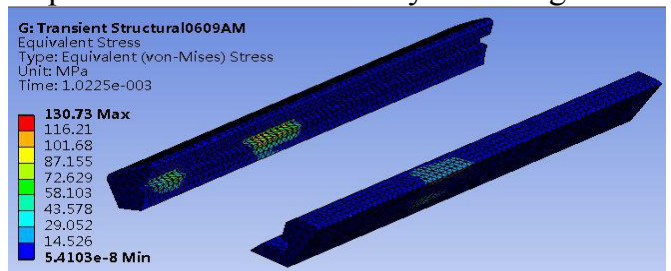

Figure 18 the general rail stress analysis

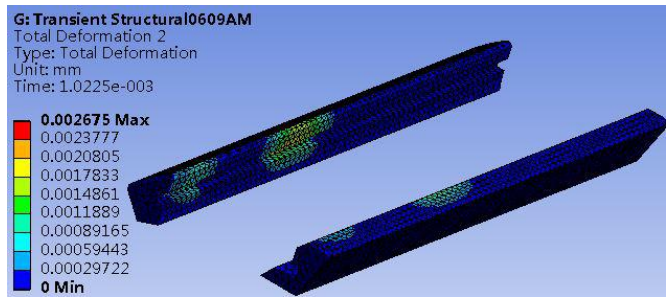

Figure 19 the general rail displacement analysis

\subsection{4 the bionics rail and the bionics bolt}

The bionics rail and the bionics bolt, the stress and displacement results are analyzed as Fig 20-21

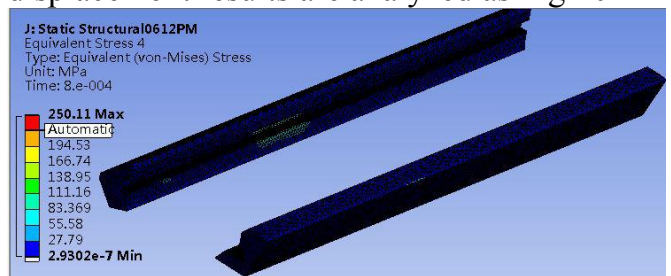

Figure 20 The bionics rail stress analysis

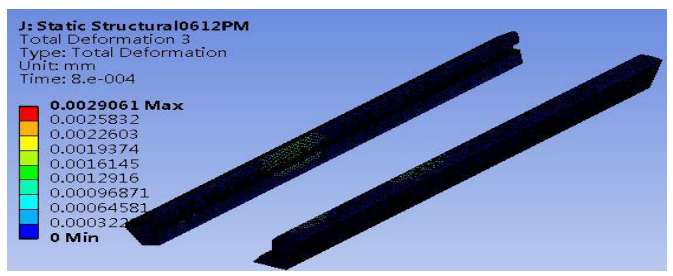

Figure 21 The bionics rail displacement analysis

\subsubsection{The conclusions for stress and displacement}

Thus it will work with $222.13 \mathrm{Mpa}$ contact stress as Figure 14, and with the additional width dimension of its rail, the rail works at $194.69 \mathrm{Mpa}$ as Figure 16:

There is table 2 which shows that the bionics rail and general rail and general bolt and bionics bolt:

Table 2. Stress and Displacement of rail

\begin{tabular}{ccclcl}
\hline Rail & Bolt & $\begin{array}{l}\text { Rail stress } \\
\text { /Mpa }\end{array}$ & $\begin{array}{l}\text { Rail } \\
\text { /mm }\end{array}$ & DX & Figure \\
\hline $\mathrm{g}$ & $\mathrm{g}$ & 222.38 & 0.0010382 & 14,15 \\
$\mathrm{~b}$ & $\mathrm{~g}$ & 194.69 & 0.0017869 & 16,17 \\
$\mathrm{~g}$ & $\mathrm{~b}$ & 130.73 & 0.002675 & 18,19 \\
$\mathrm{~b}$ & $\mathrm{~b}$ & 250.11 & 0.0029061 & 20,21 \\
\hline
\end{tabular}

Where: g- general b-bionics

From Figure 14 to Figure 18, the stress reduction is beneficial, thus the reduction rate $\delta$ :

$\delta=1-130.73 / 222.13=41.1 \%$

Displacement is big than the general guide rail, the rate of increase $\xi$ :

$\xi=0.0016368 \mathrm{~mm}$ 
For the bionic rail and bionic bolt component, the rail stress is $250.11 \mathrm{MPa}$, the rail displacement is 0.0029061 , here, the two components are bionic, and the stress is higher.

The rail displacement is always $0.001 \mathrm{~mm}$ as Fig.21, thus the reduction rate $\delta$ illustrates the effect of the bionic hole, which reaches a position higher than $10 \%$ and amazing, and the displacement is unchanged. In this way, in order to reduce the driving force, the bionics bolt can be used.

The existence of the small hole[33-34] reduces the contact area, and then reduces the contact of the surface micro convex body, and reduces the adhesive wear between the bolt and the guide rail under heavy loading. The small hole structure can store the air, which is easy to exchange heat between scraper and middle plate and surrounding air, and easy to dissipate friction heat.

\section{2 the thermal situation}

Table 2 shows the bolt and guide rail stress which is used in the 10000 firing rate, and thus the thermal situation was done with it.

The bionics bolt and general guide rail thermal situation were from Table 2, the following situation was as figure 22 and figure 23. From figure 23, there is two figure about the thermal situation, because the front is viewed from the front, and the second is viewed from the back.

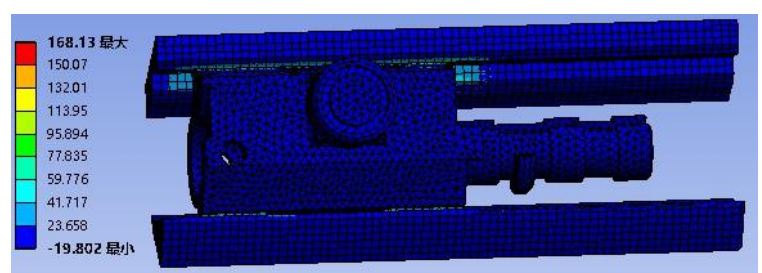

Figure 22 the general guide rail and bionics bolt thermal situation
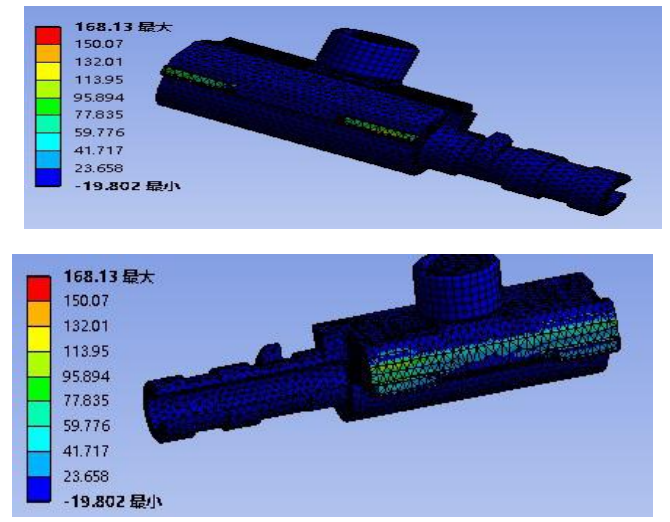

(a) Bionics bolt thermal situation

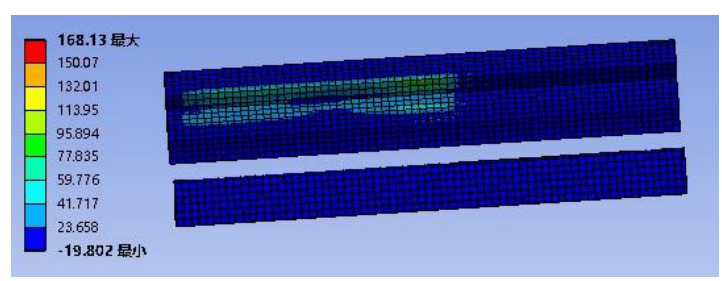

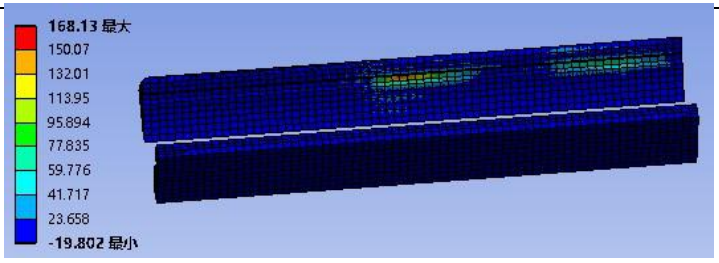

(b) the general guide rail thermal situation

Figure 23 The bionics bolt and the general guide rail thermal situation

Then the thermal situation of the general bolt and general guide rail was Figure 24 and Figure 25:

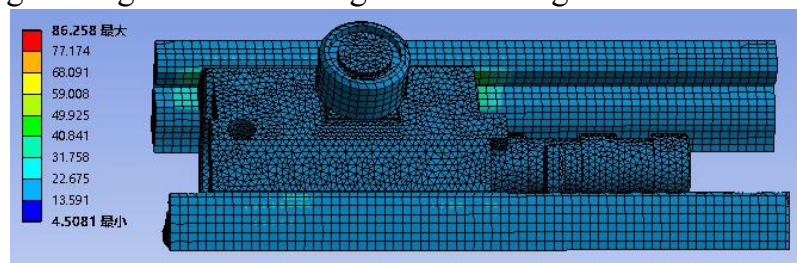

Figure 24 The general guide rail and the general bolt thermal situation
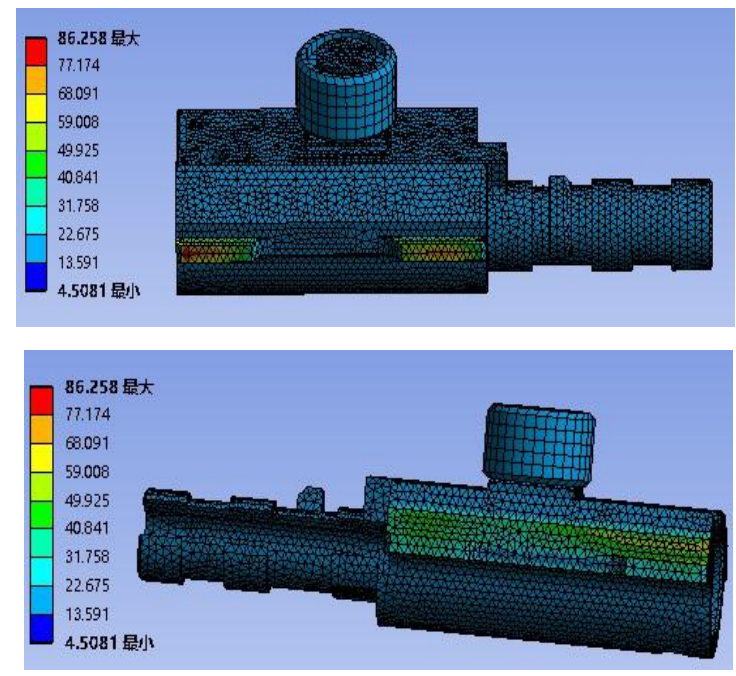

(a)the general bolt thermal situation
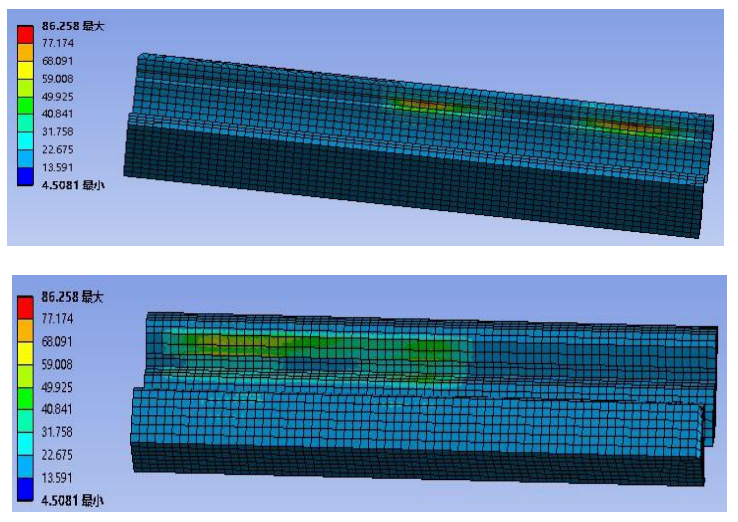

(b)The general guide rail thermal situation

Figure 25 The general bolt and the general guide rail thermal situation

And there are Table. 3 which shows the thermal situation: 
Table 3. Thermal situation

\begin{tabular}{cccc}
\hline Rail & Bolt & Thermal Situation & Figure \\
\hline $\mathrm{g}$ & $\mathrm{b}$ & 168.13 & 22,23 \\
\hline $\mathrm{g}$ & $\mathrm{g}$ & 86.258 & 24,25 \\
\hline
\end{tabular}

The situation is showing the thermal situation, the combination comes from the general guide rail and the bionics bolt is 168.130 , but the combination comes from the general guide rail and the general bolt is 86.2580 .

This temperature rise explains in fact that modern weapons don't mimic themselves on guide rails. The bolt-rail system is shown which is used in 10000 firing rate, and if you slow down the firing rate, there's still hope for bionic devices.

\section{Test and Data}

Every shooting period in 10000 firing rate, the electronic temperature wireless sensor meter will be placed in the rotating tube weapon case, and the oscilloscope will be placed outside. By starting the motor, the body will rotate in the guide rail to test the temperature.

Through the test, the DAT data is transformed as shown in figure 26 below:

Figure 26 Thermal situation in 10000 firing rate

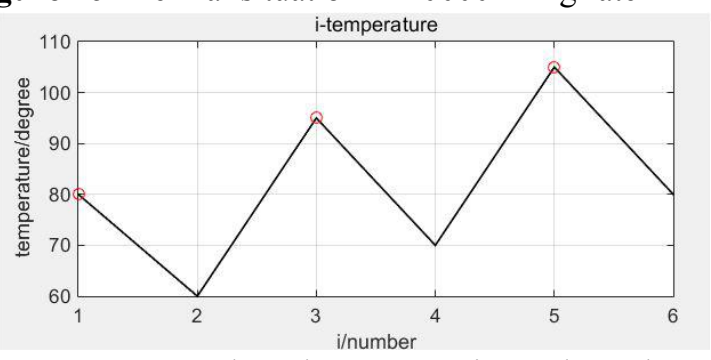

Because $\mathrm{N}$ barrels are rotating when the Gatling weapon is firing, the horizontal axis is recorded, and one head moves back and forth in the guide rail, so there are two values, so the step-by-step guide rail has a very high temperature. The number of consecutive shots is $\mathrm{N}$ times that of the red point of figure 26 in this one.

\section{Conclusion and discussion}

\section{1 conclusion}

(1)From the analysis of the Gatling weapon, the bionic theory is good than the surface roughness, especially for the bolt.

(2)The bionic bolt is good at super-high fire ratio. The bionic, as a small slot between them, show an effect and an advantage in heat dissipation. When the firing rate is 10000 , the reduction rate of stress is up to $41.1 \%$. This bionic bolt is suitable for FR more than 10,000.

(3) From Table 2, the best situation has been achieved by the bionic bolt and the general guide rail. but from Table
3 in the 10000 firing rate, the general guide rail and general bolt have the advantage of temperature.

\subsection{Discussion}

This temperature rise explains in fact that modern weapons don't mimic themselves on guide rails. The bolt-guide rail system is shown which is used in 10000 firing rate, and if you slow down the firing rate, there's still hope for bionic devices.

\section{Declarations}

\section{Availability of data and materials}

no

\section{Competing interests}

The authors declare no competing financial interests.

\section{Funding}

National Science Foundation of China Grant \#51175481

Hubei Sannong Science and Technology Talents Project 2020-2021.

\section{Autor's contributions}

\section{1 , frtiction stress 2 . roughness 3 . bionics}

\section{Acknowledgment}

The authors are grateful to the National Science Foundation of China Grant \#51175481 and Hubei Sannong Science and Technology Talents Project 2020-2021.

\section{Disclosure statement}

No potential conflict of interest was reported by the authors

\section{Consent for publication}

Not applicable

\section{Ethics approval and consent to participate}

Not applicable 


\section{Reference}

[1] Han Lichao . A Calculation Formula of Static Frictional Coefficient of Sliding Bearings and Its Practical Significance. Journal Wuhan Univ. Of Hydr. \& Elec[J]. Eng. 1998,1:110-111

[2]Wang Guoqiang, Ma Ruoding and Liu Juyuan. Study on the Coefficient of Dynamic Friction Between Frictional Metal Material[J].Transactions of the CSAE,1997, 13 (1): 35-38

[3]Wang Zhicheng, Fan De'en. An Analysis of Coefficient of Sliding Friction and its physical interpretation[J]. Journal of Shanghai Institute of Mechanical Engineering .1988, 1:65-73.

[4]Gong ZhongLiang, Huang Ping. A calculating model of sliding friction coefficient based on non-continuous energy dissipation[J]. Acta Phys. Sin. 2011, 60(2):389-394

[5]Liu Shengfu, Liu Yingkai. Measurement of the rolling friction coefficient of the cylinder[J] .Physical experient of college. 2017, 2:58-61

[6]Guo Jianting. The Mechanism of producing Rolling Friction Force and Its calculation[J]. Lubrication Engineering. 1988, 1:19-24

[7]Delprete C, Razavykia A, Baldissera P. Detailed analysis of piston secondary motion and tribological performance[J].INTERNATIONAL JOURNAL OF ENGINE RESEARCH.2020,21(9):1647-1661

[8]Delprete C, Razavykia A. Piston ring-liner lubrication and tribological performance evaluation: a review[J]. $J$ Eng Tribol. 2018; 232(2): 193-209.

[9]Rahman Seifi, Kaveh Abbasi, Masood Asayesh.Effects of Contact Surface Roughness of Interference Shaft/Bush Joints on its Characteristics[J]. Iran J Sci Technol Trans Mech Eng. (2018) 42:279-292

[10]Yuan Yuan; Gan Li; Liu Kai; Yang Xiaohui. Elastoplastic contact mechanics model of rough surface based on fractal theory[J]. Chinese Journal of Mechanical Engineering, 2017,30(1): 207-215

[11]Delprete, C, Razavykia, A. Piston ring/liner lubrication and tribological performance evaluation: a review[J]. Proc IMechE Part J:J Engneering Tribology. 2018,232(2):193-209

[12] Xinxin Li, Zhimin Li, Sun Jin, Jichang Zhang, Zhihua Niu, Jinyu Liu.Contact Properties Research for Linear Sliding Guide Rail With the Fractal Theory[J]. ASME 2019 International Mechanical Engineering Congress and Exposition.10832-10840

[13]Cao, Shunxin; Zhang, Ruijun; Zhang, Shuohua; Qiao, Shuai; Cong, Dongsheng; Dong, Mingxiao.Roller-rail parameters on the transverse vibration characteristics of super-high-speed elevators[J].Transactions of the Canadian Society for Mechanical Engineering, 2019; 43(4): 535-543
[14]Jamil A,Kambiz F . Elastic-plastic contact model for rough surfaces based on plastic asperity concept[J].International Journal of Non-linear Mechanics, 2005, 40(4): 495-506

[15]US ARMY. Engineering Design Handbook: Autoweapon design. U.S ARMY MATERIEL COMMAND. 1970. AMCP 706-260

[16] Jian Xu. Research on Dynamics Analysis and Reducing Power Consumption for Super-high Fire Ratio Gatling Gun[D]. Taiyuan: North University of China, 2010

[17]Mikhail V. Murashov, Sergey D. Panin.Numerical modelling of contact heat transfer problem with work hardened rough surfaces. International Journal of Heat and Mass Transfer. 2015,(90):72-80

[18]Chen HUI,Chen Haobo,Hu Yuzhong, Wang Hui. The Generation of Three Dimensional Rough Surface and the Control of Texture Feature[J]. LUBRICATION ENGINEERING.2007.32(8): 42-45

[19] Yan W,Kormvopoulos K. Contact analysis of elasticplastic fractal surfaces[J]. Jounal of Applied Physics, 1998,84(7):3617-3621

[20]Prasanta Sahoo and Niloy Ghosh. Finite element contact analysis of fractal Surfaces[J]. JOURNAL OF PHYSICS D. 40 (2007) 4245-4252

[21]Xu Zhiqian, Yan Xiangzhen, Yang Xiujuan, Yin Xiaokang,Wang mingda. Desacription of rough surfaces' Geometric Morphology characteristics with Fractal Parameter[J]. Lubrication Engineering.2015,40(9):1-9

[22]Li Xiaobing, Liu Ying. The computation methods of the fractal demension of surface profiles[J]. Journal of Nanchang University(Natural Science).2006. 30(1):84-86

[23]Xing Boqiang. The finite element analysis and applicaitons of rough-smooth surface contact state base on fractal characterization[M]. Qianghuangdao: Yanshan University. 2011. 20-21 (in Chinese)

[24]Bowen Chen. Geometric Modeling and contact analysis of Rough Surface[M]. Xi'an:Xidian University.2014 (in Chinese)

[25]Yang Zhuojuan. Research of Wear-resistance on Roller with Biomimetical Non-smooth Concave Surface[D]. Changchun: Jilin University. 2006.(in Chinese)

[26]D. J. Whitehouse, J. F. Archard. The properties of random surfaces of significance in their contact[J]. Proceeding of the Royal Society of London. Series A, Mathematical and Physical Sciences, 1970, 316 (1524):97-121

[27]Y Z Hu, K Tonder. Simulation of 3-D random surface by 2-D digital filter and Fourier analysis[J]. Int $J$ Mach Tools Manuf, 1992, 32:82 - 90

[28]Riadh Elleuch, Khaled Elleuch, Houcine Ben Abdelounis, Hassan Zahouani.Surface roughness effect on friction behavior of elastomeric material[J].Materials Science and Engineering.2007.465:8-12 
[29]J.J Granepain.Fractal approach to two-dimensional and three-dimensional surface roughness[J].Wear.109(1986)119-126

[30] A. MAJUMDAR and C. L. TIEN .Fractal Characterization and Simulation of Rough Surfaces[J].WEAR.1990.36:313-327

[31]Zhengkun Cheng, Ridong Liao, Delin Sun and Yuting Li. The effect of fractal surface topography on stress concentration factor[J]. Chinese Journal of Solid Mechanics.2015,3(6):251-257 (in Chinese)

[32]Binbin Liu. Study on Morphological Feature Extraction and Geometric Modeling of Rough Surfaces[D]. Fuzhou: Fuzhou University. 2017 (in Chinese)

[33]T R Thomas. Rough Surfaces.(Second Edition)[M]. London: Imperial College Press, 1999

[34]Di HU. Parameters Identification, contact analysis and Prediction of Fractal Rough Surface[D].Xi'an:Xidian University.2014 